\title{
Aylluyachiy: novo olhar sobre inculturação e Teologia Índia
}

David Mesquiati de Oliveira

\section{Resumo}

Aylluyachiy é uma expressão dos povos quéchuas que significa "tornar-se parente". É a ação de mover-se em direção a um seio familiar para dele participar. É a busca por comunhão mais íntima. Vai além da noção de tolerância ou de política da boa vizinhança. Quer sentir-se verdadeiramente "parente", "irmão". Este texto busca refletir sobre a inculturação da fé em contextos indígenas a partir desse "emparentar-se" (aylluyachiy). Inicia analisando uma imagem bíblica dessa perspectiva, quando Ananias vai ao encontro do Saulo perseguidor em casa de Judas e o chama "irmão" (Atos 9.17). Depois, a partir da história, indica que o reconhecimento dos povos indígenas como originários e como irmãos-maiores trás uma nova perspectiva para o diálogo inter-religioso e para a missão. Como caçulas, precisamos ter a humildade de não querer ensinar todas as coisas, mas a partir da experiência da fé cristã que vivemos culturalmente, compartilhar em amor fraterno a boa nova de Cristo, reconhecendo os muitos caminhos de Deus. Por ultimo, analisa criticamente alguns aspectos do processo de inculturação, enfatizando que não se trata de uma estratégia de evangelização, mas de ver nas pessoas que compõem as culturas os sujeitos da sua própria história. Pessoas maduras capazes de interação e diálogo aberto. 
Palavras-chave: Inculturação; Indígenas; Teologia Índia.

\begin{abstract}
Aylluyachiy is an expression of peoples Quechua means "become relative". It is the action of moving toward a family environment to participate. It is the search for closer communion. It goes beyond the notion of tolerance or policy of good neighborliness. Want to feel truly "relative", "brother." This paper reflects upon the inculturation of the faith in indigenous contexts from that "to a relative" (aylluyachiy). Start by analyzing a biblical image of this view, when Ananias goes to meet Saul the persecutor into the house of Judas and calls him "brother" (Acts 9:17). Then, from the history, indicates that the recognition of indigenous peoples as original and as brothers-largest behind a new perspective for interreligious dialogue and mission. As cadets, we must have the humility not want to teach all things, but from the experience of Christian faith that we live culturally, in brotherly love to share the good news of Christ, recognizing the many ways of God. Finally, critically reviews some aspects of the inculturation process, emphasizing that it is not a strategy for evangelization, but to see people in the cultures that make up the subjects of their own history. Mature people capable of interaction and open dialogue.
\end{abstract}

Keywords: Inculturation; Indigenous; Theology India.

\title{
Introdução
}

Os povos indígenas, bem como outros grupos humanos, foram vistos durante muitos séculos como mais um alvo missionário. As igrejas, tanto católicas como protestantes, se lançaram em vários projetos pela conversão desses povos. Nesse afã, solaparam as religiões ancestrais e fecharam os olhos para toda ação de Deus fora dos padrões "aceitos" dentro do cristianismo ocidentalizado. Esse texto é um convite para um novo olhar sobre a missão entre povos indígenas. A partir da palavra-expressão quéchua aylluyachiy analisa os desdobramentos de se excursionar por novos caminhos que promovam o encontro com diferentes religiões. Entende a inculturação a partir da reciprocidade e faz desse modelo um caminhoresposta teológico que fortalece a identidade dos povos e grupos sociais, cujo projeto histórico de vida está ameaçado. Aponta para a constatação de 


\begin{abstract}
"somos todos irmãos" e que precisamos construir caminhos em direção ao outro, estreitar laços.
\end{abstract}

\title{
"Saulo, meu irmão"
}

Do encontro entre Ananias e Saulo temos o seguinte registro:

Ananias foi. Entrou na casa e, impondo-lhe as mãos, disse: Saulo, meu irmão, o Senhor, esse Jesus que te apareceu no caminho, enviou-me para que recobres a vista e fiques cheio do Espírito Santo (Atos 9.17).

No seu encontro com Saulo, Ananias impondo-lhe as mãos chama-lhe "irmão" (grego adelphe). Deve ter sido um choque para Saulo passar por mais esta experiência. A imposição de mãos no livro de Atos é mencionada para conferir autoridade para um cargo (6.6), para comunicar o dom do Espírito (8.17), para o envio a uma missão (13.3) e para a cura de enfermos (28.8). Neste caso $(9.12,17)$, havia algo mais: "pela imposição de mãos de Ananias sobre Paulo, este identificou-se com o povo ao qual antes perseguia" . Toda animosidade havia cedido, e Ananias aceita a Saulo de coração como um irmão em $\mathrm{Cristo}^{2}$. Aquele momento foi singular para ambos.

Chamar Saulo de irmão mostra, por um lado, o quanto Ananias creu na conversão de Saulo. A palavra de Deus e sua visão eram tão reais que não cabiam dúvidas. Deus estava chamando aquele homem. Não importara o que fizera, Deus iria restaurá-lo. Era abertamente um inimigo. Ainda assim Ananias foi-lhe ao encontro.

Por outro lado, era uma recepção calorosa, reconhecendo Saulo como membro na nova comunidade. Após três dias sem comer e em um estado de cegueira, Saulo estava debilitado, abatido, frustrado e até sem esperança. Foi uma palavra de graça para Saulo, que agora era visto com desconfiança por ambos os grupos. Tal palavra, acompanhada da acolhida comprometida de Ananias, fez eco na vida e obra de Saulo.

Se Saulo tinha pesquisado alguma coisa sobre os líderes cristãos em Damasco, sabia do nome de Ananias. Aquele era alguém para o qual seu zelo religioso havia feito despertar o ódio. Havia planejado seu fim, matá-lo. Agora

\footnotetext{
${ }^{1}$ RYRIE, Charles C. A Bíblia anotada. São Paulo: Mundo Cristão, 1999, p. 1373.

${ }^{2}$ ROBERTSON, A. T. Comentario al texto griego del Nuevo Testamento. Barcelona: CLIE, 2003, p. 300.
} 
o que escuta é "você é meu irmão". Aquela palavra era reconciliadora. Ao mesmo tempo, libertadora. Libertava Saulo do remorso pela perseguição. Liberava-o de carregar este peso. Ele tinha muito a aprender com o amor fraterno identitário dos cristãos (novo mandamento, João 13.33-35).

Estavam unidos pela mesma visão de Deus. Tratava-se do mesmo Jesus que aparecera no caminho de Damasco. Esse Jesus era o elo, o vínculo perfeito. Ele era o que unia os dois. Essa nova comunidade que Cristo proporcionou é assombrosamente diferente. Nela podem estar juntos, perseguido e perseguidor, escravo e senhor, trabalhador e patrão, homem e mulher, rico ou pobre, judeu e gentio. Ela fomenta um novo agir, transformado, guiado pela renovação do Espírito.

No cumprimento da nossa missão nunca podemos esquecer que as pessoas as quais vamos nos relacionar são de fato seres humanos. A questão da alteridade é fundamental. Não se trata de um objetivo missionário impessoal. São pessoas, não se trata de estatísticas ou números. Precisam ser nossos "irmãos". Infelizmente, essa irmandade não tem caracterizado as comunidades cristãs ao longo da história. Portanto, não se trata de inovar, mas de resgatar o que nos é próprio como cristãos, sob o novo mandamento do amar uns aos outros. É um olhar diferente para aqueles que sempre estiveram a nossa volta. Quem primeiro precisaria mudar somos nós.

\section{Irmãos mais velhos}

Esquecemos muito rapidamente que os indígenas são povos originários nestas terras, conhecidas por alguns desses grupos como Abya Yala ("terra madura", "viva" ou "em florescimento"), antes de ser arbitrariamente chamada de "América" ou "Novo Mundo" pelo colonizador europeu3. Reconhecer os povos indígenas como "irmãos" seria um grande passo. No entanto, há ainda um segundo passo: eles são "irmãos mais velhos". Como deveria ser o relacionamento entre os irmãos? Como afeta nossas culturas, identidades e religiões?

A América Indígena, na verdade, não foi descoberta, foi invadida, e acho que daria para dizer melhor ainda: ela foi encoberta - como fala o padre Meliá - e é hora de a gente descobrir essa América indígena que foi

${ }^{3}$ LÓPEZ-HERNÁNDEZ, Míguel Angel. Encuentros en los senderos de Abya Yala. Quito: ABYA YALA, 2004, p. 4. 
encoberta, encobriu-se a língua indígena, encobriu-se a economia indígena e, especialmente, encobriu-se a religião indígena ${ }^{4}$.

Urge descobrir essa América Indígena forçada a se ocultar. Eduardo Castro afirma que no começo da evangelização dos indígenas se pensou que eram povos sem religião, pois não tinham as mesmas estruturas de hierarquia, nem de ídolos nem de poder tal como a religião européia. Acreditava-se tratar de povos como papel em branco, em que se podia imprimir a nova fé sem restrições - primeiras cartas de Manoel da Nóbrega ${ }^{5}$. Com o passar dos anos, esse preconceito e ignorância deu lugar ao estereotipo do selvagem inconstante, que rapidamente volta aos seus hábitos pagãos, pois não atendia um dos pressupostos básicos da catequese do século 16: a essência da crença era a obediência. E continua: "quando tiveram sucesso em converter os índios, a estratégia foi mudar seus costumes, hábitos. Com isso, mudava-se também a cultura deles. Para aceitar o cristianismo era preciso transculturá-los, transformá-los em não-índios. Para pregar foi preciso desidentizar". ${ }^{6}$

Agora, novos movimentos dão-nos conta de que estamos vivendo uma fase distinta. Com o reconhecimento da pluralidade cultural e religiosa, os povos indígenas estão recuperando seu espaço. Também a teologia precisa encontrar novas expressões e sistematizações que dêem conta dos novos agentes. A chamada teologia índia não tem que ser inventada, pois as culturas milenares já fazem suas reflexões desde que existiram como povo. A teologia índia (ou teologias índias) precisa ser respeitada, encorajada e reconhecida. Fazer os povos indígenas abrir mão das suas raízes ancestrais pode trazer conseqüências graves para integridade, identidade e história dessas pessoas e povos.

Eleazar Hernández afirma:

Mas também é preciso lembrar que os povos indígenas podem deixar a Igreja se perceberem que ela não oferece um lugar digno para eles e para

\footnotetext{
${ }^{4}$ ALTMANN, Lori. Fé e cultura: a evangelização e outras culturas. In: KEMPER, Thomas \& SILVA, Jaider B. de (orgs.). Repensando a evangelização junto aos povos indígenas. $41^{\text {a }}$ semana welesyana 19 a 22 de maio de 1992. São Bernardo do Campo: Editeo, 1994, p. 49.

5 CASTRO, Eduardo Viveiros de. O papel da religião no sistema social dos povos indígenas. Cuiabá: GTME, 1999, p. 10s.

${ }^{6}$ CASTRO, 1999, p. 29.
} 
a sua cultura. È um fato inegável que o mundo religioso indígena tem possibilidades de futuro não só dentro, mas também fora da Igreja. ${ }^{7}$

Mas os irmãos mais velhos não são auto-suficientes ou autônomos/independentes. $\mathrm{O}$ mundo que nos tocou viver exige capacidade para interação e diálogo. Os povos indígenas também têm muito a aprender com o caminhar milenar das igrejas. É certo que nossa teologia ocidental tem limitações, por vezes se equivocou e não raras vezes fez opção pela intolerância e violência. A visão que temos é parcial, quase uma mera interpretação. Vemos muito pouco claramente. Mas é certo que vemos. Deus nunca deixou de se revelar. Também não deixou de fazê-lo em meio aos povos indígenas. Isto é motivo de sobra para investirmos mais nos relacionamentos/missão do tipo "irmão".

\section{Aylluyachiy}

Aylluyachiy é uma palavra quéchua - importante língua da região dos Andes. Inge Sichra aponta algumas características desse idioma:

O quéchua não é "qualquer" língua. Está amparado em uma historia de "língua geral" do império incaico e sua impressionante expansão geográfica; ela se escreve por primeira vez no século XVI quando, novamente, vive uma difusão além das fronteiras do império invadido e além dos seus usos orais em boca e livros dos invasores espanhóis. Estuda-se desde então e por dois séculos em uma cátedra na Universidade de São Marcos em Lima (desde 1579) e também em Quito (desde 1581). Sua histórica difusão durante o Tawantinsuyu e a Colônia significou um forte substrato para o castelhano de toda a região, gerando-se um assim chamado espanhol andino. O quéchua é falado tradicionalmente em Bolívia, Peru y Equador, Norte de Argentina, Suroeste de Colômbia, incluindo Bogotá, em comunidades em Antofagasta, Chile, e na região do Acre em Brasil. Seus falantes são milhões (entre 8 e 12 milhões) na região andina, mas também em bolsões de migração em cidades capitais como Buenos Aires e Lima e na região amazônica. O quéchua entrou com notória vitalidade em âmbitos comerciais (feiras e mercados, quadras em Cochabamba), político-administrativos (em Cuzco), profissionais (migrantes em Virginia), educativos (em Equador, Peru y Bolívia), meios

${ }^{7}$ LÓPEZ HERNÁNDEZ, Eleazar. Deus, tradições indígenas e globalização. In: SUSIN, Luiz Carlo (org.). Teologia para Outro Mundo Possível. São Paulo, 2006, p. 316. 
de comunicação. O quéchua cumpre funções cotidianas comunitárias, domésticas ou privadas, religiosas, rituais, musicais e literárias. E voltando aos espaços públicos formais, foi declarada como língua oficial (Bolívia e Peru) ou de uso oficial; dos múltiplos alfabetos que se propuseram desde que se começou a escrever, se avançou nos anos 80 a decretar um alfabeto "normalizado" em Bolívia, Peru e "unificado" no Equador. ${ }^{8}$

Aylluyachiy é uma expressão que significa "tornar-se parente". É a ação de mover-se em direção a um seio familiar para dele participar. Em um sentido estrito, é a dinâmica das famílias ao promoverem os casamentos, acolhendo o genro ou nora como familiares, parentes. Em sentido amplo, é a busca por comunhão mais íntima. Vai além da noção de tolerância ou de política da boa vizinhança. Quer sentir-se verdadeiramente "parente", "irmão".

O tipo de diálogo requerido entre igrejas e povos indígenas tem muitas facetas. Os dois lados têm suas questões particulares e ressentimentos. O orgulho norteou a ação dos dois grupos historicamente. As igrejas terminaram se impondo, como dominantes e até, em alguns casos, como opressora e conquistadora. É preciso mais que tolerar um ao outro nesse novo momento. É requerido um verdadeiro diálogo 9 e é importante a reparação ${ }^{10}$.

Para dialogar sem medo ou preconceito é preciso escutar o outro. Perceber um Deus revelado a ambos e com expectativas sobre todos. Eleazar López Hernández afirma:

A diversidade cultural e religiosa, quando é autêntica, não conduz a outro senão ao próprio e único Deus de todos os povos. E este Deus, cujo nome Moisés conhecerá depois como Javé (eu sou aquele que sou), tem a capacidade de incluir todas as denominações de Deus, porque Ele é Elohim (Deuses). ${ }^{11}$

A religiosidade indígena tem sua forma própria de interpretar o sobrenatural. Não está apoiada em uma sistematização teológica ou em uma estrutura eclesial.

${ }^{8}$ SICHRA, Inge. Cultura escrita quechua en Bolivia: contradicción en los tiempos del poder. Tellus, ano 8, n. 15, jul./dez. Campo Grande - MS, 2008, p. 12.

${ }^{9}$ Cf. HÜTTNER, Édison. A Igreja Católica e os Povos do Brasil: os Ticuna da Amazônia. Porto Alegre: EDIPUCRS, 2007.

${ }^{10}$ Cf. BOFF, Leonardo. América Latina: da conquista à nova evangelização. São Paulo: Ática, 1992.

${ }^{11}$ LÓPEZ HERNÁNDEZ, Eleazar. Povos da Bíblia e povos índios hoje. Uma reflexão de fé para servidores dos povos indígenas. Ribla. A palavra se fez índia. n. 26. Petrópolis: Vozes; São Leopoldo: Sinodal, 1997, p. 22. 
Sua relação com o divino ou Grande Espírito ${ }^{12}$ é aberta, inclusiva ${ }^{13}$. Sua forma de adoração é aberta, "não é direcionada por nomes, estruturas ou proselitismo, mas pela aceitação do culto do outro, que procura sempre somar, nunca dividir"14. Lucio Flores sugere que essa é a chave para se entender os povos indígenas. Eduardo Castro aponta alguns caminhos para a missão entre povos indígenas ${ }^{15}$ : É preciso maior aproximação com os indígenas. Ajudá-los a aprender outros idiomas, ler, escrever. Não podemos deixá-los isolados no mato. Esse é um dos pontos da missão;

$\checkmark$ As culturas não são estáticas. No encontro de culturas eles serão influenciados pelas novas culturas. Não há como evitar. Inclusive é nessa dinâmica que eles poderão atualizar e manter sua cultura relevante para seu grupo;

$\checkmark \quad$ O missionário não pode ter medo de apresentar sua fé (religião). Os índios são crescidos o suficiente para assimilar o que cremos e decidir sobre o que querem. Alguns para não influenciar os índios se calam. Isso é ruim. A troca é importante. A menos que pensemos que eles são imaturos;

$\checkmark \quad$ É muita pretensão achar que por falar em Deus com um grupo eles serão mudados imediatamente. Um culto não muda a vida das pessoas. Elas precisam assimilar as coisas. Reinterpretar;

$\checkmark$ Para uma relação aberta, é importante que conheçamos os índios, bem como deles nos conhecerem;

$\checkmark \quad$ Entre os Xavantes havia uma missão salesiana. Um segundo grupo de missionários veio com a idéia de não-intervenção. Ao se negar a batizar os filhos recém-nascidos, foram acusados de racista. Os índios queriam o batismo não porque tivesse uma teoria sobre a salvação ou porque fosse católico. Sabia que os brancos discriminam as pessoas pela sua religião e não queriam ser discriminados. Queria ser tratado como gente. Estava usando um símbolo que sabia que era importante para o branco;

$\checkmark \quad \mathrm{O}$ mesmo passou com as roupas. Colocam roupa porque sabem que os brancos acham vergonhoso andar nu. Eles não tinham vergonha de andar $\mathrm{nu}$, mas sabe que sem roupa os brancos os tratariam como selvagens;

\footnotetext{
${ }^{12}$ Grande Espírito é uma expressão aceita entre vários povos indígenas para designarem Deus.

${ }^{13}$ FLORES, Lucio Paiva. Adoradores do Sol: reflexões sobre a religiosidade indígena. Petrópolis: Vozes, 2003, p. 12.

${ }^{14}$ FLORES, 2003, p. 13

${ }^{15}$ CASTRO, 1999, p. 31-36.
} 
As culturas têm o direito de ouvir o evangelho e devem ter a liberdade de aceita-lo ou não. É fundamental a opção de escolher. O direito de escolher é diferente da obrigação de escolher. Não deveríamos entrar forçosamente nas tribos mais distantes. Isso requer tempo;

$\checkmark$ Também é preciso cautela com a evangelização indireta, visível no assistencialismo ou no disfarce educacional. O poder que tem as sociedades dos brancos exerce uma imposição implícita sobre os indígenas.

A partir do exposto a inculturação da fé entre os povos indígenas traria permanentes benefícios se acontecesse a partir do emparentar-se com o outro "índio". Fazer-se da família. Não como simples estratégia, buscando maior penetrabilidade para convertê-los. Mas corajosamente fazer-se índio. Entender as razões das suas milenares esperanças. Permitir-se estar ligados a eles, sem possibilidade de "divórcio". Unir-se. Crescer juntos ${ }^{16}$. Encontrar Deus juntos.

\section{Conclusão}

A inculturação influenciada pelo aylluyachiy quéchua promoverá mais integração entre igreja e povos indígenas. Esta inculturação constitui-se em prática libertadora, transformadora e humanizadora. Rompe com práticas anteriores, apesar de ainda convivermos com teologias dominadoras e de mentalidade de conquistas, que estão longe de perceberem que nosso chamado primeiro consiste em amar, e não em fazer prosélitos. A relação entre indígenas e essas igrejas sob o aylluyachiy não será de estranhos e desconfiados, mas de irmãos, parentes. Não porque nasceram irmãos, mas porque se decidiram por isso. Foram em direção ao outro. Fazem seus caminhos propositalmente se cruzarem. Essa intimidade familiar permite florescer uma teologia índia onde os preconceitos são minimizados em nome dos laços afetivos e da decisão por comunhão. Palavras de ordem são partilha e solidariedade. Propicia a experiência do Deus-comunhão, reconciliador, Jesus. Sua identificação foi tão radical que ele deu sua vida pelos seus amigos (João 15.13). Somos capazes de tamanha identificação com os povos indígenas? Se começarmos a vê-los

${ }^{16}$ OLIVEIRA, David Mesquiati de. Missão, cultura e transformação. São Leopoldo: Sinodal; Quito: CLAI, 2011, p. 142s. 
como nossos irmãos, e mais velhos (respeito), as palavras de Jesus podem virar realidade na igreja missionária do século 21 .

\section{Referências Bibliográficas}

ALTMANN, Lori. Fé e cultura: a evangelização e outras culturas. In: KEMPER, Thomas \& SILVA, Jaider B. de (orgs.). Repensando a evangelização junto aos povos indígenas. $41^{\mathrm{a}}$ semana welesyana 19 a 22 de maio de 1992. São Bernardo do Campo: Editeo, 1994.

BOFF, Leonardo. América Latina: da conquista à nova evangelização. São Paulo: Ática, 1992.

CASTRO, Eduardo Viveiros de. O papel da religião no sistema social dos povos indigenas. Cuiabá: GTME, 1999.

FLORES, Lucio Paiva. Adoradores do Sol: reflexões sobre a religiosidade indígena. Petrópolis: Vozes, 2003.

HÜTTNER, Édison. A Igreja Católica e os Povos do Brasil: os Ticuna da Amazônia. Porto Alegre: EDIPUCRS, 2007.

Instituto Nacional de Estadística INE. Censo Nacional de Población y Vivienda. La Paz: INE, 2002.

LÓPEZ HERNÁNDEZ, Eleazar. Povos da Bíblia e povos índios hoje. Uma reflexão de fé para servidores dos povos indígenas. Ribla. A palavra se fez índia. n. 26. Petrópolis: Vozes; São Leopoldo: Sinodal, 1997, p. 16-24.

. Deus, tradições indígenas e globalização. In: SUSIN, Luiz Carlo (org.). Teologia para Outro Mundo Possivel. São Paulo, 2006.

LÓPEZ-HERNÁNDEZ, Míguel Angel. Encuentros en los senderos de Abya Yala. Quito: ABYA YALA, 2004.

MAIA, Marcus. A revitalização de línguas indígenas e seu desafio para a educação intercultural bilíngüe. Tellus, ano 6, n. 11, out. Campo Grande - MS, 2006, p. 61-76.

MARZAL, Manuel M. Sincretismo iberoamericano e inculturación. Medellín, vol. 15, n. 60, dez. 1989.

MIRANDA, M de França. Inculturação da fé: uma abordagem teológica. São Paulo: Loyola, 2001.

MOLINA, Ramiro; ALBÓ, Xavier (coords.). Gama étnica y lingüistica de la población boliviana. La Paz: Sistema de las Naciones Unidas en Bolivia, 2005. 
OLIVEIRA, David Mesquiati de. Missão, cultura e transformação. São Leopoldo: Sinodal; Quito: CLAI, 2011.

ROBERTSON, A. T. Comentario al texto griego del Nuevo Testamento. Barcelona: CLIE, 2003.

RYRIE, Charles C. A Bíblia anotada. São Paulo: Mundo Cristão, 1999.

SICHRA, Inge. Cultura escrita quechua en Bolivia: contradicción en los tiempos del poder. Tellus, ano 8, n. 15, jul./dez. Campo Grande - MS, 2008, p. 11-34.

\begin{abstract}
David Mesquiati de Oliveira
Doutorando em Teologia pela PUC-Rio, Mestre em Teologia pela Faculdades EST.

Professor no Mestrado Profissional em Ciências das Religiões na Faculdade Unida de Vitória-ES e na graduação em Teologia na mesma faculdade. Foi missionário entre os quéchuas na Bolívia de 2001 a 2006.

E-mail: david@faculdadeunida.com.br
\end{abstract}

Artigo Recebido em 22/08/2011

Artigo Aprovado em 25/11/2011 